\title{
O PROCESSO CIVIL COMO INSTRUMENTO PARA CONCRETIZAÇÃO DO DIREITO FUNDAMENTAL DE ACESSO À JUSTIÇA
}

\section{CIVIL PROCEDURE AS AN INSTRUMENT OF ACCOMPLISHMENT OF THE FUNDAMENTAL RIGHT OF ACESS TO JUSTICE}

\author{
Thais Aranda Barrozo" \\ Vicente de Paula Marques Filho"
}

\begin{abstract}
Resumo: O texto analisa o papel do processo civil como instrumento para concretização de direitos fundamentais, neles incluído o de acesso à justiça. Trata das tutelas jurídica e jurisdicional dos direitos fundamentais no modelo estatal vigente, com destaque à necessidade de busca de meios que garantam efetividade à norma constitucional, para que se cumpra a tarefa estatal concretizadora. Aponta, ao final, o ativismo judicial e a utilização de novas técnicas processuais, mais adequadas à finalidade de efetivação de direitos fundamentais, como possível caminho para que o processo sirva, de fato, como instrumento para realização de justiça social.
\end{abstract}

Palavras-chave: Direitos fundamentais. Acesso à justiça. Efetividade.

\begin{abstract}
This text analyzes the role of civil procedure as an instrument to accomplish fundamental rights, including the access to justice. It deals with legal and jurisdictional tutelage of fundamental rights in current model of State, focusing on the necessity of searching for means that guarantee effectiveness to the constitutional rules, then, fulfilling the State's tasks. It exposes that the judicial activism and the use of new procedural techniques, more adjusted to the purpose of giving effectiveness to the fundamental rights, as possible means to guarantee that civil procedure can be employed, in fact, as an instrument to accomplish social justice.
\end{abstract}

Key-words: Fundamental rights. Access to Justice. Effectiveness.

"Mestre em Direito Negocial (área: Direito Processual Civil) pela UEL (2011). Especialista em Direito Empresarial (área: Direito Tributário) pela PUC/PR (2004). Especialista em Filosofia Política e Jurídica pela UEL (2002). Graduada em Direito pela Universidade Estadual de Londrina (1998). Email: thaisaranda@sercomtel.com.br " Possui graduação em Direito pela Universidade Estadual de Londrina (1992), mestrado em Direito Negocial pela Universidade Estadual de Londrina (1999) e doutorado em Direito pela Pontifícia Universidade Católica de São Paulo (2006). Tem experiência na área de Direito, com ênfase em Direito Civil. Email: vicente@marquesdiniz.com.br 


\section{INTRODUÇÃO}

A ordem constitucional de 1988, ao declarar expressamente o Brasil um Estado Democrático de Direito, firmemente ocupado com a tutela jurídica e jurisdicional dos direitos fundamentais, passou a exigir do jurista um estudo abalizado não só do direito constitucional contemporâneo, mas também das técnicas processuais adequadas a garantir efetividade à norma constitucional, de modo que o processo possa, de fato, ser tomado como efetivo instrumento à disposição dos cidadãos para provocação da jurisdição e conseguinte concretização de direitos fundamentais.

Ante essa contingência, busca-se neste trabalho realizar um breve estudo sobre as tutelas jurídica e jurisdicional dos direitos fundamentais no novo modelo estatal, com especial destaque ao estudo do acesso à justiça como direito fundamental à espera de concretização.

Para tanto, traça-se, num primeiro momento, singela distinção entre tutela jurídica e tutela jurisdicional do Estado para, em seguida, apontar como se dá no ordenamento vigente a tutela jurídica dos direitos fundamentais, destacando ainda a problemática questão da efetividade da norma constitucional, tomada essa como a sua eficácia social.

Trata, também, da tutela jurisdicional dos direitos fundamentais, apontando o novo papel do judiciário, com uma postura mais ativa do que tradicionalmente observada, na tarefa de garantir-lhes maior efetividade, demonstrando, ao final, a necessidade da busca de novas técnicas processuais para tutela e efetividade do próprio direito fundamental de acesso à justiça.

\section{TUTELA JURÍDICA E TUTELA JURISDICIONAL}

Antes de adentrar no tema objeto do presente estudo, imperioso se traçar ligeira distinção entre tutela jurídica e tutela jurisdicional, para que seja possível, após, aferir como tais tarefas são desempenhadas pelo Estado no modelo vigente, quando se tem por foco a necessária concretização dos direitos fundamentais.

Nesse desiderato, o início do estudo se dá com apoio nas lições de Cândido Rangel Dinamarco (1996, p. 61), que conceitua a tutela jurídica como a "proteção que o Estado confere ao homem para a consecução de situações consideradas eticamente desejáveis segundo os valores vigentes na sociedade - seja em relação aos bens, seja em relação aos outros membros do convívio". Corresponde, pois, diretamente à idéia de proteção que o Estado confere aos direitos materialmente subjetivos, no intuito de servir a seu papel de modelador da conduta humana em sociedade. 
Daí dizer-se que, ao prestar a tutela jurídica aos cidadãos, o Estado cria um arcabouço de normas jurídicas (regras e princípios), que prevêem, de forma geral e abstrata, as condutas almejadas para o bem viver e efetivo desenvolvimento de uma sociedade harmônica ${ }^{1}$.

A tutela jurisdicional, de sua vez, implica na prestação da atividade da jurisdição em favor do titular desse direito substantivo amparado pela norma jurídica, caracterizando, pois, a atuação do Direito nos casos concretos trazidos à apreciação e julgamento pelo Poder Judiciário, com vistas à eliminação do conflito de interesses e, de conseguinte, à pacificação social.

Ainda, com apoio nas lições de Cândido Rangel Dinamarco (1996, p. 61):

Tutela jurisdicional é o amparo que, por obra dos juízes, o Estado ministra a quem tem razão num processo. Tutela é ajuda, proteção. É jurisdicional a proteção outorgada mediante o exercício da jurisdição, para que o sujeito, beneficiado por ela obtenha, na realidade da vida e das relações com as coisas ou com outras pessoas, uma situação mais favorável do que aquela em que antes se encontrava. [...] compete aos órgãos jurisdicionais outorgar essa proteção àquele cuja pretensão seja merecedora dela.

Feitas essas considerações preliminares, o estudo ruma com a análise da proteção, jurídica e jurisdicional, prestada pelo Estado aos direitos fundamentais, com vistas a evidenciar porque também o acesso à justiça há que ser tomado como direito fundamental, apontando-se, ainda, alternativas para que se alcance cada vez mais sua concretude.

\section{TUTELA JURÍDICA DOS DIREITOS FUNDAMENTAIS}

\subsection{Dignidade Humana, Direitos Humanos e Direitos Fundamentais}

O estudo da dignidade humana e sua estreita vinculação aos "direitos fundamentais não pode passar ao largo do enfrentamento da questão acerca da própria conceituação dessas figuras jurídicas, devendo analisar também, se a expressão "direitos humanos" confunde-se ou não com elas.

Essencial, portanto, que se parta de uma conceituação dessas expressões - dignidade humana, direitos humanos e direitos fundamentais -, tarefa esta inegavelmente árdua em vista da dificuldade que se põe no encontro de um significado satisfatório de "dignidade humana".

${ }^{1}$ Conforme lições de Dinamarco (1996, p. 61), "A definição das regras de convivência está no plano do que se denomina direito material e revela-se nas técnicas pelas quais se definem abstratamente situações de vantagem ou de desvantagem de um indivíduo ou grupo de indivíduos perante outro e em relação a algum bem da vida”. 
A ideia que se tinha de dignidade humana nos séculos XVII e XVIII relacionase diretamente à de "liberdade do ser humano de optar de acordo com sua razão e agir conforme o seu entendimento e sua opção" (SARLET, 2008, p. 33). No pensamento kantiano sobre a natureza racional do ser humano, esse ideário se revela com a primazia da autonomia da vontade, entendida como "A faculdade de determinar a si mesmo e agir em conformidade com a representação de certas leis" (KANT, 2002, p. 67). Considerando o homem - único e insubstituível - um fim em si mesmo, dono da sua liberdade de agir em conformidade com as leis livremente escolhidas pela sua própria razão, Kant (2002, p. 77) assim explica o significado e o alcance da "dignidade" que aí reside:

No reino dos fins tudo tem um preço ou uma dignidade. Quando uma coisa tem um preço, pode pôr-se em vez dela qualquer outra coisa como equivalente, mas quando uma coisa está acima de todo o preço, e portanto não permite equivalente, então tem ela dignidade.

No século XIX, o pensamento de Hegel (apud SARLET, 2008, p. 38) aponta para uma nova forma de se reconhecer a dignidade humana, fundamentando sua ideia de dignidade na de eticidade, sintetizando concreto e universal, individual e comunitário, de modo que o ser humano não é ontologicamente digno, e sim se torna digno quando adquire sua condição de cidadão, quando respeita e é respeitado pelos demais como sujeito na comunidade em que inserido.

Característica marcante do século XX é o papel de destaque que a dignidade da pessoa humana ocupa nos pensamentos filosófico, político e jurídico, assumindo, nessa fase, uma condição de valor fundamental para os mais diversos Estados constitucionais que se queiram democráticos, que acabam por preconizar o homem enquanto "titular de direitos que devem ser reconhecidos e respeitados por seus semelhantes e pelo Estado” (SARLET, 2008, p. 40).

Como se vê, o conceito de dignidade humana, além de vago e abstrato, apresenta-se, pois, em processo de constante construção e desenvolvimento.

A despeito dessa circunstância, considerando que a dignidade humana engloba a ideia de valor fundamental do cidadão (independentemente da definição jurídica que se venha posteriormente a lhe dar), adota-se no presente texto a conceituação de dignidade humana proposta por Sarlet, em que se reconhece o cidadão enquanto titular de direitos mínimos e essenciais que lhe assegurem uma sobrevivência digna, objeto de reconhecimento pelos demais cidadãos e pelo próprio Estado.

A dignidade da pessoa humana assume, pois, status de verdadeiro direito do cidadão em relação ao Estado, e de correspondente dever, deste em relação àquele, de assegurar um mínimo existencial que lhe permita viver dignamente 
na sociedade em que inserido, observando-se, ainda, estreita vinculação entre ela e os direitos fundamentais ${ }^{2}$.

A concepção de direitos fundamentais que se adota neste estudo é aquela apresentada por Bonavides (2003, p. 560-1) que, num sentido amplo, ligaos umbelicalmente à de dignidade da pessoa humana, numa relação de instrumentalidade dos primeiros à concretização da última; e, num sentido mais estrito, mais normativa, aponta os direitos fundamentais como aqueles assim qualificados pelo direito vigente.

Ou seja, a caracterização dos direitos fundamentais, tomando por base um critério formal, aponta que "direitos fundamentais" são aqueles previstos como tais na norma constitucional e que dela recebem um grau maior de segurança, seja pela previsão da sua imutabilidade ou, ao menos, pelo estabelecimento de critérios mais rígidos que dificultem sua mudança (BONAVIDES, 2003, p. 561). No entanto, materialmente considerados, os direitos fundamentais "variam conforme a ideologia, a modalidade do Estado, a espécie de valores e princípios que a Constituição consagra" (BONAVIDES, 2003, p. 561), de modo que cada Estado tem, por livre escolha e opção, direitos fundamentais específicos.

$\mathrm{E}$, ainda que haja um núcleo mínimo comum nas normas constitucionais dos países que adotam o paradigma democrático-constitucional, haverá sempre um mínimo a diferenciar e caracterizar individualmente cada Estado, ou seja, um "núcleo mínimo de direitos sociais-fundamentais plasmados em cada texto que atendam ao cumprimento das promessas da modernidade" (STRECK, 2004, p. 134-5).

No caso brasileiro, o rol de direitos fundamentais encartados na Constituição Federal de 1988 sob forma de princípios ou de regras, vinculam-se e destinamse à concretização dos princípios fundamentais gerais espelhados nos incisos no art. $1^{\circ}$ da Constituição Federal, dentre os quais se encontra a dignidade da pessoa humana, pilar e substrato do princípio maior do Estado Democrático

\footnotetext{
${ }^{2}$ Nas palavras de Ingo Wolfgang Sarlet $(2008$, p. 27), "em se levando em conta que a dignidade, acima de tudo, diz com a condição humana do ser humano, cuida-se de assunto de perene relevância e atualidade, tão perene e atual for a própria existência humana. Aliás, apenas quando (e se) o ser humano viesse ou pudesse renunciar à sua condição é que se poderia cogitar da absoluta desnecessidade de qualquer preocupação com a temática ora versada. Todavia, justamente pelo fato de que a dignidade vem sendo considerada (pelo menos para muitos e mesmo que não exclusivamente) qualidade intrínseca e indissociável de todo e qualquer ser humano e certos de que a destruição de um implicaria a destruição do outro, é que o respeito e a proteção da dignidade da pessoa (de cada uma e de todas as pessoas) constituem-se (ou, ao menos, assim o deveriam) em meta permanente da humanidade, do Estado e do Direito.”
} 
de Direito. Aliás, como bem ressaltado por Luís Roberto Barroso (2009, p. 251), a dignidade humana, prevista no art. 1ํ, III, da Constituição Federal, como um dos fundamentos da República, "está na origem dos direitos materialmente fundamentais e representa o núcleo essencial de cada um deles, assim os individuais como os políticos e os sociais".

Vista, então, essa estreita vinculação dos "direitos fundamentais" ao princípio da "dignidade humana", resta verificar se aqueles, seja em sua concepção formal ou na material, podem ser tomados como sinônimos da expressão "direitos humanos".

Ao tratar da evolução histórica dos direitos humanos, aponta Fábio Konder Comparato (2007, p. 58) a redundância contida nessa expressão, por entender inegável que os direitos são inerentes à própria condição humana no estágio atual do pensamento filosófico e jurídico, "sem ligação com particularidades determinadas de indivíduos ou grupos". A distinção que se faz entre "direitos humanos" e "direitos fundamentais" decorre, pois, da normatividade e efetividade dos primeiros no meio social. Nessa ordem de ideias, é possível afirmar que os direitos fundamentais são os direitos humanos reconhecidos pelas autoridades políticas encarregadas da elaboração das normas jurídicas, que os incluem em suas regulamentações internas e externas ${ }^{3}$.

Ainda a respeito da distinção entre "direitos fundamentais" e "direitos humanos", aponta Sarlet (2001, p. 33) que os primeiros são aqueles "reconhecidos e positivados na esfera do direito constitucional positivo de determinado Estado", enquanto que os segundos referem-se a "posições jurídicas que se reconhecem ao ser humano como tal, independentemente de sua vinculação com determinada ordem constitucional". Logo, os direitos humanos revelam um caráter mais universal, que transcende o tempo e o espaço ${ }^{4}$.

Guerra Filho (2000, p. 98-9), de sua vez, procede à distinção apontando os direitos fundamentais como "manifestações positivas do direito, com aptidão para a produção de efeitos no mundo jurídico", e identifica os direitos humanos como "pautas ético-políticas, situados em uma dimensão supra positiva, deonticamente diversa daquela em que se situam as normas jurídicas especialmente aquelas de direito interno".

${ }^{3}$ Segundo Comparato (2007, p. 58-9), "são os direitos humanos positivados nas Constituições, nas leis, nos tratados internacionais. Segundo outra terminologia, falase em direitos fundamentais típicos e atípicos, sendo estes os direitos humanos ainda não declarados em textos normativos".

${ }^{4}$ Para Sarlet (2001, p. 33), os direitos humanos "aspiram à validade universal, para todos os povos e tempos, de tal sorte que revelam um inequívoco caráter supranacional (internacional)". 
E se é pela positivação da norma jurídica que se outorga obrigatoriedade ao direito subjetivo nela espelhado, parece correto afirmar que os "direitos fundamentais” são direitos inerentes à própria condição humana, reconhecidos pela autoridade política competente através da sua positivação, que exercem importante "função pedagógica no seio da comunidade, no sentido de fazer prevalecer os grandes valores éticos, os quais, sem o reconhecimento oficial, tardariam a se impor na vida coletiva" (COMPARATO, 2007, p. 58).

Conclui-se, assim, que estabelecida a "dignidade humana" como meta almejada pelo Estado Democrático de Direito brasileiro, que a instituiu como um de seus princípios fundantes, a Constituição Federal de 1988 elencou um rol de direitos mínimos dos cidadãos, a ser respeitado por todos, indistintamente, inclusive pelo próprio Estado. Tratam-se, pois, de "direitos humanos", positivados na norma constitucional. "Direitos fundamentais", portanto, destinados à concretização do princípio maior da "dignidade humana".

Essa é a relação - e estreita vinculação - que se estabelece entre as três figuras analisadas.

\subsection{Evolução Histórica da Tutela Jurídica dos Direitos Fundamentais}

Tomando os "direitos fundamentais" como instrumento para a concretização da "dignidade humana", esses - até mesmo por uma questão de lógica -, tal qual se verifica com a conceituação da "dignidade humana", encontram-se em processo de contínua construção ao longo da evolução histórica.

As classificações adotadas pela doutrina utilizam-se dos termos "gerações" ou "dimensões" para demonstração dessa mutação ao longo do tempo, sendo de comum consenso falar-se na existência de três gerações de direitos, observando-se, no entanto, classificações que apontam para a existência de outras mais, falando-se em quarta, quinta e até mesmo sexta geração dos direitos fundamentais. Não se nega, contudo, independentemente da classificação que se adote, o caráter cumulativo do processo de evolução, de modo que os novos direitos fundamentais agregam-se aos já reconhecidos pela ordem jurídica, de maneira complementar (SARLET, 2001, p. 49)5.

A classificação ora apresentada é aquela adotada por Paulo Bonavides, que classifica os direitos fundamentais em quatro dimensões. Vejamos.

${ }^{5}$ Por essa razão a crítica da moderna doutrina ao uso do termo "gerações", dizendo-se de maior precisão técnica o uso do termo "dimensões", haja vista que "o uso da expressão 'gerações' pode ensejar a falsa impressão da substituição gradativa de uma geração por outra” (SARLET, 2001, p. 49). 
O racionalismo francês da Revolução de 1789 conduziu à elaboração de uma Declaração dos Direitos do Homem, em que se prescreveu, num modo universalista, a liberdade e a dignidade como ideais para toda e qualquer pessoa, tendo tal declaração, como destinatário, todo o gênero humano (BONAVIDES, 2003, p. 562). Escolhidos, pois, pela sociedade os valores universais essenciais à dignidade humana, resumidos basicamente nos princípios norteadores da Revolução Francesa (liberdade, igualdade e fraternidade), cumpriu ao Direito acompanhar essa transformação social, através da inserção de tais valores na esfera normativa. A liberdade, elemento essencial e princípio fundante de qualquer sociedade que prime pela promoção e respeito à dignidade humana, serve de baluarte aos direitos fundamentais de primeira dimensão, traduzidos em verdadeiras faculdades subjetivas do cidadão correlatas ao seu direito de resistência ou de oposição perante o Estado (BONAVIDES, 2003, p. 564).

Numa visão típica do Estado de Direito Liberal, caracterizado pelo individualismo do pensamento liberal-burguês do século XVIII, os direitos fundamentais de primeira dimensão afirmam-se e são reconhecidos nas primeiras Constituições escritas como "direitos do indivíduo frente ao Estado, mais especificamente como direitos de defesa, demarcando uma zona de nãointervenção do Estado e uma esfera de autonomia individual em face de seu poder” (SARLET, 2001, p. 50). Apresentam-se, assim, e em sua maior parte, como direitos de cunho negativo, "dirigidos a uma abstenção, e não a uma conduta positiva por parte dos poderes públicos” (SARLET, 2001, p. 50).

Portanto, falar em direitos fundamentais, em direitos do homem de primeira dimensão, corresponde diretamente à ideia de salvaguarda da sua valorização pessoal, subjetiva e abstrata, em relação ao poder estatal, por meio do reconhecimento do status constitucional, formal e material, desses direitos (SARLET, 2001, p. 39).

A partir do século XX, com o advento de distintas formas de Estados sociais, emerge a valorização de um outro grupo de direitos, fundados agora no princípio de igualdade: os direitos sociais, culturais, econômicos e de coletividades. São, pois, apontados como direitos de segunda dimensão.

A despeito da sua inegável relevância para concretização da almejada dignidade humana, tais direitos, por sua própria natureza, por muitas vezes carecem de eficácia, pois que "exigem do Estado determinadas prestações materiais nem sempre resgatáveis por exigüidade, carência ou limitação essencial de meios e recursos" (BONAVIDES, 2003, p. 564). Daí a afirmação de que "Não se cuida mais, portanto, de liberdade do e perante o Estado, e sim de liberdade por intermédio do Estado” (SARLET, 2001, p. 51), razão pela qual não há como se desconsiderar o caráter liberal que ainda carregam. 
Passaram por uma fase em que remetidos à esfera programática da ordem constitucional, isso querendo dizer que sua concretização não dispunha dos mesmos meios processuais de proteção como se vira com os direitos de liberdade (direitos fundamentais de primeira geração), situação essa modificada com a formulação nas constituições, como é o caso da brasileira, do preceito de aplicabilidade imediata de tais direitos ${ }^{6}$ (BONAVIDES, 2003, p. 564).

É bem verdade que nesse contexto entram em cena discussões acerca da impossibilidade de efetivação desses direitos por falta e/ou escassez de recursos, apontando-se um caráter utópico de tais direitos, o que exige, sem desconsiderar a força normativa e imperatividade dos mesmos, que se abandone a ideia de constituição dirigente tal qual originariamente concebida, quando se afirmava a aplicabilidade e vinculatividade plenas desses direitos. Aliás, a esse respeito, oportunas as lições de Luís Roberto Barroso (2009, p. 220), no sentido de que

Diante de excessos irrealizáveis, a tendência do intérprete é negar o caráter vinculativo da norma, distorcendo, por esse raciocínio, a forma normativa da Constituição. As ordens constitucionais devem ser cumpridas em toda a extensão possível. Ocorrendo a impossibilidade fática ou jurídica, deve o intérprete declarar tal situação, deixando de aplicar a norma por esse fundamento e não por falta de normatividade. Aí estarão em cena conceitos como reserva do possível, princípios orçamentários, separação dos Poderes, dentre outros. Como já assinalado, certas normas podem ter sua aplicabilidade mitigada por outras normas ou pela realidade subjacente.

Tendo por baluarte o ideal revolucionário de fraternidade, de solidariedade, observa-se forte sedimentação ao final do século XX de uma nova dimensão de direitos fundamentais, tomados como direitos fundamentais de terceira dimensão. O teor humanitário e universalista desses é ainda maior que os demais, e seu destinatário não é mais um indivíduo, uma coletividade, um Estado, e sim todo o gênero humano. Englobam o direito à paz, ao desenvolvimento, ao meio ambiente, à comunicação e ao patrimônio comum da humanidade (BONAVIDES, 2003, p. 569; SARLET, 2001, p. 53).

Da globalização política e econômica emergem os direitos fundamentais de quarta dimensão, quais sejam: o direito à democracia, à informação e ao

${ }^{6}$ CRFB, "Art. 5․ Todos são iguais perante a lei, sem distinção de qualquer natureza, garantindo-se aos brasileiros e aos estrangeiros residentes no País a inviolabilidade do direito à vida, à liberdade, à igualdade, à segurança e à propriedade, nos termos seguintes:

[...]

$\S 1^{\circ}$ - As normas definidoras dos direitos e garantias fundamentais têm aplicação imediata." 
pluralismo (BONAVIDES, 2003, p. 571). Tais direitos abarcam todos os das demais dimensões, podendo-se dizer que constituem o ápice da pirâmide composta por todos eles, irradiando-se por e através deles. Até mesmo porque, os direitos fundamentais "gravitam, direta ou indiretamente, em torno dos tradicionais e perenes valores da vida, liberdade, igualdade e fraternidade (solidariedade), tendo, na sua base, o princípio maior da dignidade da pessoa" (SARLET, 2001, p. 54).

Essa é, em breve síntese, a classificação procedida por Bonavides para a evolução histórica dos direitos fundamentais, cabendo ressaltar que as classificações adotadas pela doutrina não são estanques e que o reconhecimento ao longo da história de uma nova classe de direitos fundamentais não exclui, em absoluto, $\mathrm{a}(\mathrm{s})$ anterior(es). Pelo contrário: uma vai se agregando à outra, de forma cumulativa, enrobustecendo todo o conjunto de direitos fundamentais.

\subsection{A Efetividade da Norma Constitucional e o Acesso à Justiça como Direito Fundamental}

Segundo lições de Konrad Hesse (1992, p. 12), no modelo democrático-social contemporâneo, a vida social torna-se impossível sem uma atividade estatal organizadora, bem como, ao inverso, o Estado democrático não se constitui sem uma cooperação social, observando-se estreita relação entre as vidas social e estatal no processo de formação de uma unidade política. De conseguinte, se a unidade política depende da atuação conjunta da sociedade e do próprio Estado, a este cabe organizar a realização das tarefas estatais e o bom andamento dessa cooperação, por meio de um ordenamento jurídico apto a essa finalidade (HESSE, 1992, p. 13-4).

Nesse cenário, de extrema relevância a questão da efetividade da norma constitucional, assim entendida como a sua eficácia social, não se podendo mais, na contemporaneidade, pensar a norma fundamental de um Estado como um simples rol de prescrições valorativas e abstratas, desprovidas de qualquer sanção pelo seu descumprimento, ou ainda, como um "mero ideário sem eficácia jurídica” (BARROSO, 2009, p. 219). A norma constitucional há que ser pensada como norma jurídica dotada não só de imperatividade, mas, sobretudo, da mais ampla efetividade, de modo que ela, de fato, sirva à ordenação e conformação do contexto social e político de uma comunidade.

Observa-se, assim, o surgimento da doutrina da efetividade, que deu novos contornos ao direito constitucional, tanto na teoria como na prática, destacando-se, no âmbito jurídico, a atribuição de força normativa plena à norma constitucional e, no âmbito institucional, conferindo papel de destaque 
ao Judiciário, com uma postura mais ativa diante da tarefa de concretizar direitos e valores espelhados na norma constitucional (BARROSO, 2009, p. 224). Afinal, os direitos fundamentais não podem mais ser vistos apenas como norte valorativo e principial a ser perseguido, reconhecendo-se a necessidade de efetivação dos mesmos, munindo-se o ordenamento de instrumentos jurídicos que permitam ao cidadão exigir do Estado a execução de políticas públicas que garantam condições mínimas à preservação do princípio da dignidade humana, inclusive com a previsão de meios de acesso à Jurisdição para essa finalidade?

Daí a distinção traçada por Canotilho (2004, p. 76) entre direito à proteção jurídica e direito de defesa, sendo o primeiro aquele que o titular do direito fundamental tem de exigir do Estado uma proteção perante agressões por outros cidadãos, enquanto que o segundo se revela como o direito de exigir que o próprio Estado não ofenda os direitos fundamentais dos cidadãos (defendendose, pois, em relação a ele). Aponta, ainda, Canotilho (2004, p. 77), que o direito de defesa abarca um direito a prestações do Estado, consubstanciado no dever de "conformação e ordenação, pelo Estado, das relações jurídicas privadas, de modo a evitar a violação de direitos, e criação de instrumentos processuais ou procedimentais adequados à defesa e garantias desses direitos”.

Fixado, pois, o ponto de que a salvaguarda do princípio da dignidade humana implica no reconhecimento da necessidade de efetivação de direitos fundamentais mínimos previstos na norma constitucional, por meio de instrumentos processuais e/ou procedimentais e de uma jurisdição voltada a garantir efetividade à última, resta responder quais seriam esses "direitos fundamentais mínimos".

Entenda-se por mínimo existencial "o conjunto de bens e utilidades básicas para a subsistência física e indispensável ao desfrute dos direitos em geral” (BARROSO, 2009, p. 253). Afinal, não se garantir um mínimo para a subsistência do cidadão implica em negar não só sua dignidade, mas sua própria condição humana. Portanto, fome, miséria, exclusão social, analfabetismo, negativa de promoção da saúde e de acesso aos órgãos jurisdicionais para proteção dos direitos dos cidadãos, indicam os limites para se aferir o mínimo existencial, outorgando-se nessa seara - e não a todos os direitos sociais constitucionais,

${ }^{7}$ Como dito por Daniel Sarmento (2006, p. 49-50), "os direitos fundamentais protegem os bens jurídicos mais valiosos, e o dever do Estado não é só abster-se de ofendê-los, mas também o de promovê-los e salvaguardá-los das ameaças e ofensas provenientes de terceiros. E para um Estado que tem como tarefa mais fundamental, por imperativo constitucional, a proteção e a promoção dos direitos fundamentais dos seus cidadãos, a garantia destes direitos torna-se também um autêntico interesse público". 
indistintamente - aplicabilidade plena e imediata à norma constitucional. Conforme dito por Eduardo Cambi (2009, p. 390):

[...] quando se opta pela concretização do mínimo existencial, não se está abrindo mão de parcela dos direitos fundamentais sociais, mas apenas encontrando um modo pelo qual os direitos fundamentais possam se realizar na maior medida do possível. Dentro das limitações orçamentárias, o Estado deve priorizar os gastos públicos na concretização daqueles direitos que permitem gerar as condições gerais mínimas para a emancipação, porque essa é a premissa mais favorável à realização dos direitos fundamentais em países de modernidade tardia como o Brasil. Os demais direitos devem ser buscados no exercício democrático da cidadania reivindicatória e a prática orçamentária.

Para Luís Roberto Barroso (2009, p. 253), esse rol de "prestações que compõem o mínimo existencial comporta variação conforme a visão subjetiva de quem o elabore, mas parece haver razoável consenso de que inclui, pelo menos: renda mínima, saúde básica e educação fundamental”, agregando, ainda, a esse elenco, o direito de acesso à justiça, haja vista ser este o instrumento para exigibilidade e efetivação dos demais.

Observe-se que se forma, então, um verdadeiro círculo virtuoso, em que: a) reconhece-se a relevância ao papel ativo do judiciário na materialização de políticas públicas tendentes a assegurar um mínimo existencial a que os cidadãos vivam com dignidade, garantindo-se, assim, efetividade à norma constitucional; e b) ao assim proceder, o próprio acesso a uma ordem jurídica justa e o regular exercício da jurisdição para concretização da norma constitucional (e dos direitos fundamentais nela previstos) são elevados ao patamar de "direito fundamental".

\section{TUTELA JURISDICIONAL DOS DIREITOS FUNDAMENTAIS}

\subsection{O Papel do Judiciário na Concretização dos Direitos Fundamentais}

Da necessidade que o Estado desempenhe sua tarefa de concretização dos direitos fundamentais, a atividade judicial acaba por assumir nova roupagem, não mais se traduzindo na simples aplicação do direito nos moldes de subsunção do fato à norma jurídica. A própria sentença é considerada como norma jurídica, concreta e individual, fundamentada em normas jurídicas gerais e abstratas (as leis, em sentido lato), e se consubstancia no "ato de interpretação e aplicação do Direito pelo juiz como integrante da política do direito (Rechtspolitik), ao importar na opção por algum dos valores objetivamente consagrados na norma positiva” (GUERRA FILHO, 2001, p. 162-3).

Essa postura mais ativa do Judiciário acaba, contudo, por conduzi-lo a emitir, não raras vezes, decisões de caráter eminentemente político, o que 
levanta a problemática questão da sua legitimidade para assim proceder, já que seus membros não são democraticamente eleitos pelo povo. Figueroa (2003, p. 167) aponta a existência de críticas a essa transferência de poder ao Judiciário, ao argumento de possibilidade de ofensa ao próprio princípio democrático. Afinal, se é objetivo do Estado de Direito, fundado na ordem constitucional, a restrição do exercício arbitrário do poder pelo Estado, logo, não se deveria dotar o juiz de tamanha margem de discricionariedade na interpretação e aplicação do Direito.

A discricionariedade é, contudo, exigência da própria "natureza bifronte"8 dos princípios constitucionais, que, ainda que por um lado estabeleçam limites (irrenunciáveis) ao Estado, por outro a sua abstração confere uma margem maior de liberdade na sua interpretação e aplicação, por meio da ponderação razoável exercida pelo julgador. Logo, ainda que sejam vagos e abertos os conteúdos constitucionais, é preciso sempre compreender com critérios de razoabilidade o âmbito de atuação do Judiciário, para que a discricionariedade não dê azo à verdadeira arbitrariedade, em indubitável ofensa ao princípio democrático.

Muito se discute nesse ponto acerca da judicialização da política - e, conseqüente politização do Direito -, fenômeno este assim entendido quando se reconhece que "um processo político é ou está 'judicializado' na medida em que a jurisprudência constitucional, o receio de uma futura censura constitucional e a autoridade pedagógica da jurisprudência passada podem alterar o resultado legislativo” (MAURÍCIO JR., 2008, p. 127).

No caso brasileiro, a Constituição Federal tem uma vasta gama de normas que disciplinam a administração e regulamentação da vida pública e privada, estabelecendo garantias e direitos individuais e sociais e "invadindo espaços classicamente pertencentes ao legislador e ao administrador, bem como atribuindo extensas competências ao judiciário, as quais vêm sendo gradativamente expandidas nas últimas reformas constitucionais” (MAURÍCIO JR., 2008, p. 137).

De fato, a legitimação de um "agir político" pelo Judiciário se origina no fato da democracia e dos direitos se consubstanciarem nas bases do Estado Democrático de Direito, haja vista ser o próprio Estado, através de sua norma constitucional, que outorga competência ao Judiciário para legitimamente resguardar os fundamentos do modelo estatal, tutelando os direitos sociais fundamentais e a própria democracia (STRECK, 2004, p. 113).

${ }^{8}$ Expressão adotada por Alfonso Garcia Figueroa, citando Luis Prieto, na obra Sobre princípios y normas. Problemas del razonamiento jurídico, CEC, Madrid, 1992, p. 136. 
Enfim, ainda que "judicializando" a política e "politizando” o Direito, o que não se pode negar é a atual importância da função concretizadora do Judiciário no modelo democrático-constitucional, sendo necessário que se lhe outorgue a tarefa não só de dizer o alcance e o significado da norma constitucional, mas também de efetivar os princípios e direitos fundamentais nela contidos, com vistas a assegurar um mínimo existencial que confira aos cidadãos condições de vida digna.

\subsection{O Acesso à Justiça e a Necessidade de um Sistema Processual Adequado à Concretização de Direitos Fundamentais}

Analisando o atual papel da constituição, em contraposição àquele do Estado Liberal, aponta Willis Santiago Guerra Filho (2000, p. 16) que o anseio da sociedade contemporânea é de que a ordem constitucional reflita "linhas gerais para guiar a atividade estatal e social, no sentido de promover o bemestar individual e coletivo dos integrantes da comunidade que soberanamente a estabelece". Essa alteração do paradigma estatal e da função da norma constitucional conduz inexoravelmente a modificações do plano jurídico, sobretudo em razão de reconhecer-se validade positiva a preceitos de conteúdo altamente axiológico: os princípios fundamentais.

A ordem constitucional renovada, permeada por princípios de elevado grau de abstração - carentes, portanto, de precisão enquanto norma orientadora da conduta humana -, clama por um procedimento adequado à concretização dos mesmos, sob pena de faltar-lhes a efetividade almejada à consecução dos fins sociais do Estado. Por essa razão, a idéia de processo/procedimento liga-se, indissociavelmente, à de concretização de direitos fundamentais, e "a participação no e através do procedimento já não é um instrumento funcional e complementar da democracia, mas sim uma dimensão intrínseca dos direitos fundamentais" (CANOTILHO, 2004, p. 74) 9

Some-se a isso que, dentre os direitos a prestações do Estado encontram-se os direitos de defesa do cidadão, os quais se revelam sob forma de "direito à existência de tribunais, direito à jurisdição, direito à decisão judicial, direito à execução de sentenças judiciais" (CANOTILHO, 2004, p. 77). Logo, o direito a uma ordem processual adequada à concretização de direitos fundamentais é, igualmente, um direito fundamental e, como tal, exige efetivação ${ }^{10}$. De

9 Ainda Segundo lições de Canotilho (2004, p. 73-74), "a dogmática dos direitos fundamentais deve assumir-se também como política de direitos fundamentais processualmente concretizada ou a concretizar pelo 'Estado de prestações" 
conseguinte, a ciência processual passa a necessitar de uma adequação estrutural de sua dogmática, de modo que se conceba um "novo" processo, moldado aos imperativos de um Estado de Direito social e democrático, afastando-se do processo individualista, concebido sob as influências liberais do paradigma estatal anterior.

Observa-se, assim, na evolução da ciência processual, ante o caráter regulador prospectivo da nova ordem constitucional, o reconhecimento da origem constitucional de normas jurídicas processuais e de institutos processuais básicos, sobretudo aquelas referentes às garantias do acesso à justiça e do devido processo legal, aí incluídos o direito ao contraditório e à ampla defesa ${ }^{11}$, passando o direito processual a ser visto como "uma espécie de direito constitucional aplicado” (GUERRA FILHO, 2000, p. 25).

Daí o mútuo envolvimento observado entre a ordem constitucional e a ciência processual, seja pelo fato da norma constitucional exigir um processo adequado à concretização do direito material nela espelhado ${ }^{12}$, ou pelo cunho processual de garantias processuais reveladas sob forma de princípios. Essa mútua abrangência permite afirmar que a Constituição possui, atualmente, natureza de norma processual e os institutos fundamentais de direito processual nela previstos assumem, igualmente, natureza de direito material (GUERRA FILHO, 2000, p. 27-28).

Sobre essa relação de reciprocidade entre a norma constitucional e o processo, apontam Alvaro de Oliveira e Daniel Mitidiero (2010, p. 16) que "Correntemente, alude-se à processualização da Constituição e à materialização

${ }^{10}$ Retome-se aqui o que se disse no item anterior a respeito da necessária efetividade de direitos fundamentais destinados à promoção de um mínimo existencial, que outorgue vida digna aos cidadãos. Nas palavras de Sarlet (2008, p. 26), "Com efeito, diante do compromisso assumido formalmente pelo constituinte, pelo menos - nas hipóteses de violação dos deveres e direitos decorrentes da dignidade da pessoa restará uma perspectiva concreta, ainda que mínima, de efetivação por meio de órgãos jurisdicionais, enquanto e na medida em que se lhes assegurar as condições básicas para o cumprimento do seu desiderato".

${ }^{11}$ CRFB, “Art. 5… [...]

XXXV - a lei não excluirá da apreciação do Poder Judiciário lesão ou ameaça a direito; $[\ldots]$

LIV - ninguém será privado da sua liberdade ou de seus bens sem o devido processo legal; LV - aos litigantes, em processo judicial ou administrativo, e aos acusados em geral, são assegurados o contraditório e ampla defesa, com os meios e recursos a ela inerentes.

${ }^{12}$ Segundo Canotilho (2004, p. 78), "'[...] qualquer direito material postula uma dimensão procedimental/processual e, por isso, reconhecer um direito material constitucional implica necessariamente reconhecer um direito subjectivo do procedimento/processo indispensável para garantir a eficácia do direito material”. 
do processo como conseqüências da teoria processual da Constituição e da constitucionalização do processo". O principal reflexo desses fenômenos no direito processual é, pois, a substancialização dos valores insculpidos na norma constitucional, e o fato do formalismo, típico do processo civil do Estado Liberal, ceder lugar ao "formalismo-valorativo" do Estado Constitucional (OLIVEIRA; MITIDIERO, 2010, p. 17).

No que tange à constitucionalização do processo civil, a doutrina divide-a em dois momentos marcantes e característicos, falando-se em "primeira constitucionalização do processo", como o período em que se observa a formalização de garantias processuais na Constituição de 1988, limitadoras ao arbítrio do poder do Estado, com grande enfoque no estudo dos princípios constitucionais do processo (reconhecimento de um direito processual constitucional), e numa "segunda constitucionalização do processo", momento em que o processo civil passa a ser concebido à luz da teoria da efetividade dos direitos fundamentais, assumindo a função concretizadora já mencionada no presente estudo (OLIVEIRA; MITIDIERO, 2010, p. 17).

Emerge o processo como instrumento assegurador da efetividade do direito fundamental de acesso à justiça (efetividade da proteção judicial) e de todos os demais direitos fundamentais plasmados na norma constitucional, ocupando-se a ciência processual moderna exclusivamente da "realização concreta da justiça" (BEDAQUE, 2009, p. 56). Não que o processo perca a sua feição constitucional primeira, de proteção dos cidadãos em relação ao arbítrio do Estado, mas, sim, agrega-se a ela a sua função de garantir a aplicabilidade imediata dos direitos fundamentais, nos termos do art. $5^{\circ}, \S 1^{\circ}$, da Constituição Federal ${ }^{13}$.

Ao processualista do Estado Constitucional cabe, então, conferir uma postura mais flexibilizadora à tutela jurisdicional, e não única e essencialmente formal, para que possa lançar-se com mais arrojo na busca de "alternativas que favoreçam a resolução de conflitos de modo seguro e tempestivo, mediante tutelas aptas a afastar a crise do direito material, realizando concretamente a vontade do legislador” (BEDAQUE, 2009, p. 58).

De conseguinte, não há mais como se falar em "processo civil adequado" sem ligar essa ideia à de flexibilização das normas processuais e procedimentais

${ }^{13}$ Alvaro de Oliveira e Daniel Mitidiero (2010, p. 17-18) destacam que "o processo civil passa a emprestar relevo à autoaplicabilidade dos direitos fundamentais (CRFB, art. $\left.5^{\circ}, \S 1^{\circ}\right)$, à proibição de proteção insuficiente, de proteção excessiva e de retrocesso na proteção de direitos fundamentais, bem como à dimensão objetiva dos direitos fundamentais, cuja eficácia irradiante impõe o dever de interpretação da legislação infraconstitucional em conformidade com os direitos fundamentais". 
e de uma postura mais ativa do Judiciário, com vistas a conferir eficiência ao processo enquanto instrumento assegurador de efetividade à própria justiça material. Afinal, não basta ao jurisdicionado a mera previsão constitucional do acesso à justiça como direito fundamental do cidadão, sem que o Estado garanta, igualmente, através da reformulação de suas normas processuais, um procedimento eficaz à tutela jurisdicional efetiva.

Conforme as lições de José Roberto dos Santos Bedaque (2009, p. 74-75), o processo, enquanto instrumento para o exercício da jurisdição, será adequado a essa finalidade apenas quando, de fato, for eficiente a proporcionar tutela efetiva e eficaz aos jurisdicionados, sobremaneira porque "A utilidade do ordenamento jurídico material está intimamente relacionada com a eficácia do processo, que constitui o meio para garantir a atuação do Direito nas hipóteses de ausência de cooperação espontânea dos destinatários”. Para Alvaro de Oliveira e Daniel Mitidiero (2010, p. 16), "O juiz, mais do que ativo, deve ser cooperativo, como exigido por um modelo de democracia participativa e a nova lógica que informa a discussão judicial, ideias essas inseridas num novo conceito, o de cidadania processual".

Também Luiz Guilherme Marinoni (2008, p. 144) defende que o direito fundamental a uma tutela jurisdicional efetiva, além de ser o mais importante dos direitos fundamentais (já que é pela efetivação dele que se efetiva os demais), há que ser visto por uma ótica "tridimensional”, englobando o direito à técnica processual adequada, o direito de participação por meio de procedimento adequado e o direito à resposta jurisdicional.

Isso tudo vem apenas a corroborar a ideia de que não há mais como dissociar o discurso da efetivação dos direitos fundamentais de um procedimento idôneo e participativo, capaz de viabilizar a concretização dos mesmos. E nada disso é possível sem a devida conformação do sistema processual a essa nova realidade social.

\section{CONCLUSÃO}

O estágio atual de evolução da ciência processual exige o abandono da ideia de processo como mero instrumento de concretização do direito material, sobressaindo e fortalecendo uma concepção de processo - coerente com a teoria da efetividade dos direitos fundamentais - que vá para muito além disso: o processo há que ser visto como instrumento para promoção da efetivação da justiça material e dos direitos fundamentais (individuais, sociais, políticos etc.) insertos na ordem constitucional, destinados a assegurar um mínimo 
existencial para vida digna aos cidadãos, tudo isso com vistas ao seu fim maior, de pacificação social.

Temas como flexibilização procedimental e ativismo judiciário tornamse, assim, mais frequentes no avanço da ciência processual, não só por força da nova teoria das normas jurídicas (albergando os princípios no arcabouço jurídico) e pela necessidade de efetivação dos direitos fundamentais no Estado Constitucional, mas, sobretudo, para que a postura dialógica a ser adotada no processo permita que ele se torne palco de exercício da cidadania e, com isso, sirva como instrumento de fortalecimento da própria democracia.

Inegável, pois, a necessidade de abertura do sistema processual a novas técnicas processuais destinadas a estancar a crise do direito material. Afinal, seria um verdadeiro despautério ter-se uma ordem jurídica firmemente ocupada com a efetividade de uma vasta gama de "novos" direitos materiais (aí incluídos os direitos fundamentais, base do Estado Constitucional), e não guarnecer essa ordem jurídica de um regime processual capaz de atender a esses direitos, comprometendo, assim, a sua própria efetividade, bem como a da tutela jurisdicional adequada.

Portanto, querer tutelar os direitos fundamentais por meio do processo civil clássico - formalista, rígido e individualista -, é o mesmo que negar-lhes vigência e efetividade. Afinal, se a mudança do paradigma estatal levou à mudança do direito material, de nada servirá esse avanço (social, cultural, jurídico) se o sistema não for dotado de uma ordem processual adequada à realização dos novos direitos. Somente com a transformação do direito processual é que o Judiciário estará, de fato, munido de instrumento para que o Estado concretize o seu dever de proteção, direito este também fundamental, conforme outrora apontado, e essencial à asseguração da dignidade humana.

\section{REFERÊNCIAS}

BARROSO, Luís Roberto. Curso de direito constitucional contemporâneo: os conceitos fundamentais e a construção do novo modelo. São Paulo: Saraiva, 2009.

BEDAQUE, José Roberto dos Santos. Direito e processo: influência do direito material sobre o processo. 5. ed. rev. e ampl.. São Paulo: Malheiros Editores, 2009.

BONAVIDES, Paulo. Curso de direito constitucional. 13. ed. rev. e atual. São Paulo: Malheiros Editores, 2003.

BRASIL. Constituição (1988). Constituição da República Federativa do Brasil: 
promulgada em 5 de outubro de 1988. Contém as emendas constitucionais posteriores. Brasília, DF: Senado, 1988.

CAMBI, Eduardo. Neoconstitucionalismo e neoprocessualismo: direitos fundamentais, políticas públicas e protagonismo do judiciário. São Paulo: Ed. Revista dos Tribunais, 2009.

CANOTILHO, José Joaquim Gomes. Estudos sobre direitos fundamentais. Coimbra: Coimbra Editora, 2004.

COMPARATO, Fábio Konder. A afirmação histórica dos direitos humanos. 5. ed. rev. e atual. São Paulo: Saraiva, 2007.

DINAMARCO, Cândido Rangel. Tutela jurisdicional. Revista de Processo, São Paulo, v. 21, n. 81, p. 54-81, jan./mar. de 1996.

FIGUEROA, Alfonso García. La teoria del Derecho en Tiempos de Constitucionalismo. In: CARBONEL, Miguel (Org.). Neoconstitucionalismo(s). Madrid: Trotta, 2003.

GUERRA FILHO, Willis Santiago. Teoria processual da Constituição. São Paulo: Celso Bastos Editor: Instituto Brasileiro de Direito Constitucional, 2000. . Teoria da ciência jurídica. São Paulo: Saraiva, 2001.

HESSE, Konrad. Escritos de Derecho Constitucional. 2. ed. Madrid: Centro de Estudios Constitucionales, 1992.

KANT, Immanuel. Fundamentação da Metafísica dos Costumes. Traduzida do alemão por Paulo Quintela. Lisboa: Edições 70, 2002.

MARINONI, Luiz Guilherme. Técnica processual e tutela dos direitos. 2. ed. rev. e atual. São Paulo: RT, 2008.

MAURÍCIO JR., Alceu. Judicialização da política e a crise do direito constitucional: a constituição entre ordem marco e ordem fundamental. Revista de Direito de Estado RDE, ano 3, n. 10, p. 125-142, abr./jun. 2008.

OLIVEIRA, Carlos Alberto Alvaro de; MITIDIERO, Daniel. Curso de processo civil. Teoria geral do processo civil e parte geral do direito processual civil. São Paulo: Atlas, 2010. v. 1.

SARLET, Ingo Wolfgang. A eficácia dos direitos fundamentais. 2. ed. rev. atual. Porto Alegre: Livraria do Advogado, 2001. 
Dignidade da pessoa humana e direitos fundamentais na Constituição Federal de 1988. 6. ed. rev. e atual. Porto Alegre: Livraria do Advogado Ed., 2008.

SARMENTO, Daniel. Colisões entre direitos fundamentais e interesses públicos. In: SARLET, Ingo Wolfgang (Coord.). Jurisdição e direitos fundamentais. Porto Alegre: Escola Superior da Magistratura: Livraria do Advogado, 2006.

STRECK, Lênio Luiz. Jurisdição Constitucional e Hermenêutica: uma nova crítica do direito. 2. ed. Rio de Janeiro: Forense, 2004.

Artigo recebido em 27/09/10 e aprovado para publicação em10/11/11

Como citar: BARROZO, Thais Aranda; MARQUES FILHO, Vicente de Paula. $O$ processo civil como instrumento para concretização do direito fundamental de acesso à justiça. Scientia Iuris, Londrina, v. 15, n. 2, p. 89-108, dez. 2011. DOI: $10.5433 / 2178-8189.2011 \mathrm{v} 15 \mathrm{n} 2 \mathrm{p} 89$ 